\title{
Greens persuade Europe to revoke patent on neem tree...
}

Ulrike Hellerer, Munich

\section{K. S. Jarayaman, New Delhi}

A global coalition of environmental groups is celebrating a major victory in their fight against what they call 'biopiracy'. Last week, the European Patent Office (EPO) revoked a controversial patent on the use of antifungal agents extracted from the neem tree.

The patent was granted in 1994 to the US Department of Agriculture and the multinational agribusiness corporation W. R. Grace. But it has been fiercely contested by environmental groups, to whom it is a symbol of western multinationals' unacceptable exploitation of indigenous communities.

The neem tree (Azadirachta indica), which translates as the 'free tree', is a member of the mahogany family. It is indigenous to the Indian subcontinent, where it has been used in agriculture, medicine and cosmetics for centuries.

The EPO has received 51 patent applications for 'inventions' based on the neem tree, and has so far granted 11 . Around 90 patents exploiting the tree have been granted worldwide.

The coalition fighting the neem patent whose motto is 'Free the Free Tree' - is coordinated by the Green party in the European parliament. It includes the Indian Research Foundation for Science, Technology and Ecology, an influential environmental group, and the International Federation of Organic Agriculture Movements (IFOAM), a pressure group for organic farming.

In applying for the patent, Grace had argued that it had used an extract of the tree's seed to make a new fungicide. But the coalition claimed that Grace's patent was not sufficiently novel, as Indian farmers have used this fungicide for decades.

The EPO's opposition board accepted this interpretation, because Ajay Bio-Tech an agrochemical company in Pune, India, that has been making a neem-based fungicide since the early 1980 s - produced documents to prove that it had conducted the relevant field trials.

Protests against the patenting of neem

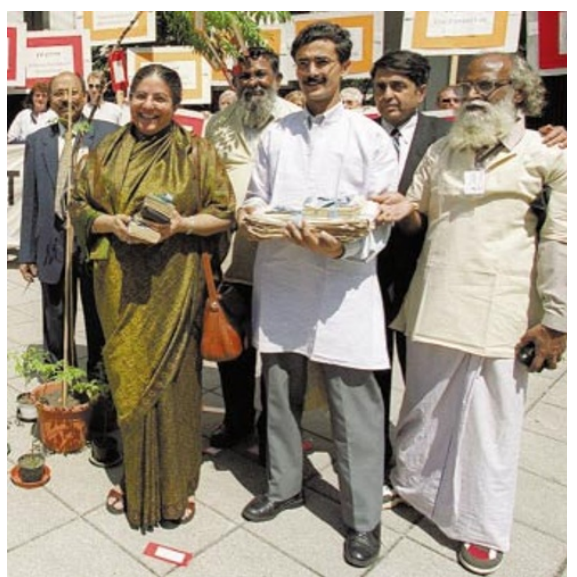

Free Tree freed: protesters celebrate their victory outside the Munich patent office.

products began in India in 1993, with one demonstration in Bangladesh numbering half a million people. The Free the Free Tree coalition filed its opposition to the patent in 1995. It also launched a petition in India in 1994, and presented the EPO with 500,000 signatures during last week's hearing.

Linda Bullard, president of IFOAM, says that the coalition lacks the resources to dispute the other ten neem-related patents granted by the EPO. But she hopes that the precedent set by last week's ruling will 
influence decisions on pending patent applications - a possibility the EPO concedes.

Ragunath Mashelkar, director-general of the Council of Scientific and Industrial Research in New Delhi, the coordinating body for India's government research laboratories, says that the decision may not have a direct influence on all cases. But he welcomes the withdrawal of the patent "in the sense that it sensitizes the world against biopiracy".

Beth Burrows, the president of the Edmonds Institute, a non-profit environmental organization near Seattle which also supported the objection, says that "broadcasting the message that the patenting system facilitates biopiracy, the appropriation of biological resources and knowledge from southern countries, was one of the coalition's main aims". She adds that the neem patent "robs the poor of the last resources that can ensure their survival".

W. R. Grace is reserving comment. It has two months to challenge the EPO's decision. Abhay Phadke, managing director of Ajay Bio-Tech, believes the decision is a step towards preventing W. R. Grace monopolizing the market in neem seed. But he points out that W. R. Grace remains in a powerful position, because it has similar patents filed in the United States.
Furthermore, the EPO's decision may not be generally applicable. Birgit Reiter, an expert in pharmaceutical and patent law at the German Association of Research-Based Pharmaceutical Companies, says that last week's technical decision will have no direct influence on the pharmaceutical industry's interest in exploiting natural products, as it was not based on a general principle about the rights to such harvesting.

But she adds that if it becomes more diffi- cult to patent natural products, "pharmaceutical companies will have to think again about whether the expense of further development and clinical trails will pay off".

The environmentalists are now happy to relax for a while. "The whole issue, and what to do next, will be discussed again at the meeting of the Biodiversity Convention in Nairobi this week," says Bullard. "The decision will give new impetus to the discussions."

\section{...as India pushes ahead with plant database}

Indian science minister Murli Manohar Joshi greeted last week's revocation of a European patent on the neem tree - which the Indians have traditionally used in medicine and agriculture almost as if it were a military victory. But his advisers know that piecemeal success will not solve the problem of 'biopiracy'.

With this in mind, India has announced plans to create a digital database of its traditional knowledge. This will be included in the patent classification system of the Geneva-based World Intellectual Property Organization (see Nature 401, 413; 1999).

The database will be available to patent offices worldwide especially in the United States and Europe - so that data on any Indian plant can be obtained before patents are issued. "This is the only permanent solution to prevent patents from being issued for non-original inventions in our traditional system," says
Ragunath Mashelkar, directorgeneral of the Council of Scientific and Industrial Research in New Delhi.

Mashelkar told Nature that the documentation of 90 indigenous plants with medicinal or industrial uses has already begun - a complete electronic database on these will be available in between six months and one year. All major plants are expected to be covered in the next two years. 